Running Head: Ostracism and Visual Awareness

\title{
The Visual Influence of Ostracism
}

Marius Golubickis, Arash Sahraie, Amelia R. Hunt, Aleksandar Visokomogilski, Pavlos Topalidis, C. Neil Macrae

School of Psychology, University of Aberdeen, Aberdeen, Scotland, UK

Word Count: 3848

Address Correspondence To:

Marius Golubickis

School of Psychology

University of Aberdeen

King's College

Aberdeen AB24 3FX

Scotland, UK

Email: marius.golubickis.10@aberdeen.ac.uk 


\begin{abstract}
Reflecting the fundamental human need to establish and maintain positive connections with others, it has been suggested that an Ostracism Detection System (ODS) is sensitized to targets by which one has been ostracized. Evidence supporting the operation of this system has yet to be provided, however. Accordingly, using binocular rivalry to explore attentional processing, here we considered the extent to which targets previously associated with ostracism dominate visual awareness. Participants initially performed a virtual ball-tossing game (i.e., Cyberball) in which they were 'ostracized' or 'included' by the other players. Afterwards, the faces of these players were presented together with houses in a binocular rivalry task. The results revealed that targets associated with ostracism (vs. inclusion) dominated longest in visual awareness.
\end{abstract}

Keywords: ostracism, Cyberball, binocular rivalry, visual awareness 
The Visual Influence of Ostracism

Ostracism — being excluded, rejected or ignored — violates the fundamental human need to belong (Baumeister \& Leary, 1995; Williams, 2007, 2009). ${ }^{1}$ Whether overlooked by the local soccer team, discarded by a potential employer or neglected by a close friend, ostracism triggers a raft of undesirable outcomes. Left on the sidelines, ostracized individuals experience anger, depression, hostility, and alienation (see DeWall \& Bushman, 2011; Williams, 2007). Self-worth and self-esteem are diminished (Williams, Cheung, \& Choi, 2000), impulse control is impaired (Baumeister, DeWall, Ciarocco, \& Twenge, 2005; Oaten, Williams, Jones, \& Zadro, 2008) and, in extreme cases, ostracism can contribute to heinous acts of societal violence, including high school shootings (Leary, Kowalski, Smith, \& Phillips, 2003). The message then is unequivocal. For one's psychological wellbeing, ostracism should be avoided.

Given the acknowledged costs of interpersonal disconnection (DeWall \& Bushman, 2011; Eisenberger, 2012), it would clearly be advantageous if people were sensitized to sources of ostracism. After all, such awareness would enable them to mobilize strategies and tactics to minimize the harmful consequences of social rejection. It is interesting to note, therefore, that an Ostracism Detection System (ODS) has been postulated to serve precisely this psychological function (Cricher \& Zayas, 2014; Spoor \& Williams, 2007; Williams, 2009; Williams \& Nida, 2011). Endorsing the viewpoint that humans have developed perceptual mechanisms to detect threats to belongingness (e.g., Kerr \& Levine, 2008; Leary \& Baumeister, 2000; Picket \& Gardner, 2005; Romero-Canyas \& Downey, 2005), the ODS is claimed to enable rapid and efficient (i.e., automatic) responses to rejection-related stimuli, including individuals associated with prior acts of ostracism. Critically, however, this theoretically important effect remains untested. Although an extensive literature has demonstrated that ostracism

\footnotetext{
${ }^{1}$ Although commonplace for the terms 'rejection,' ostracism,' and 'exclusion' to be used interchangeably, these overlapping phenomena can vary in subtle ways (Williams, 2007; Richman \& Leary, 2009). Accordingly, given reliance on the Cyberball paradigm in the current research (Williams et al., 2000), the term 'ostracism' is favored here.
} 
influences cognition and (to a lesser extent) perception (e.g., DeWall, Maner, \& Rouby, 2009; Gardner, Picket, \& Brewer, 2000; Maner, DeWall, Baumeister, \& Schaller, 2007; Picket, Gardner, \& Knowles, 2004; Sacco, Wirth, Hugenberg, Chen, \& Williams, 2011), the core prediction of the ODS - that ostracism facilitates target processing during the early stages of person appraisal — has yet to be scrutinized. Accordingly, we explored this issue in the current investigation.

That prior social experiences have the capacity to influence person perception is consistent with the contention that motivationally relevant stimuli benefit from enhanced processing (Dunning \& Balcetis, 2013). Theories of attention assert that stimulus relevance is a function of the physical properties of objects in conjunction with people's motivations, expectancies and prior learning experiences (e.g., Bar, 2004; Collins \& Olson, 2014; Fecteau \& Munoz, 2006; Lupyan, 2015). For example, stimulus desirability (hence value) has been shown to influence the detection, interpretation, and appearance of goal-relevant objects (see Dunning \& Balcetis, 2013). Comparable effects have also been reported during the person perception process. In an important study, Anderson, Siegel, BlissMoreau, and Feldman-Barrett (2011) showed that targets previously associated with undesirable (vs. desirable) gossip dominate visual awareness, thereby demonstrating the impact of social learning on attentional processing. Specifically, during periods of interocular competition (i.e., binocular rivalry) in which percepts of both positive and negative targets were potentially available, negative targets predominated. Reflecting the operation of the ODS (Spoor \& Williams, 2007; Williams, 2009; Williams \& Nida, 2011), we expect ostracism to exert similar effects. That is, targets associated with ostracism (vs. inclusion) should dominate longest in visual awareness.

Two methodologies were employed to investigate the effects of ostracism on visual attention: Cyberball and binocular rivalry (BR). Cyberball is the principal paradigm for studying the effects of ostracism in the laboratory (Hartgerink, van Beest, Wicherts, \& Williams, 2015; Williams et al., 2000) and comprises a virtual ball-tossing game that participants perform with two (occasionally three) other players: one who periodically throws the ball to the participant (i.e., 'includer') and another who does 
not (i.e., 'ostracizer'). Although other paradigms have been used to explore ostracism, such as futurelife rejection, autobiographical memory manipulations, and getting-acquainted tasks (Baumeister, Twenge, \& Nuss, 2002; Nezlek, Kowalski, Leary, Blevins, \& Holgate, 1997; Craighead, Kimball, \& Rehak, 1979), Cyberball is preferred because participants are never explicitly told they are being ostracized. As such, it serves as a relatively naturalistic and effective means of studying the effects of ostracism under laboratory-based conditions (see Hartgerink et al., 2015).

$\mathrm{BR}$ is a type of perceptual rivalry that exploits the reflexive suppression that arises when two different images are processed simultaneously (Blake, 2001). A popular technique to explore the contents of visual awareness, BR involves the presentation of dissimilar images (e.g., face \& house) to each eye (i.e., dichoptic stimulation), which then compete for perceptual dominance. Typically, one of the images breaks through and accesses conscious awareness, while the other image is suppressed. After a few seconds, the suppressed image becomes dominant (and the formerly dominant image suppressed), so that over time the viewer experiences involuntary alterations in periods of perceptual dominance between the two images (i.e., perceptual-alteration-cycles). The relative dominance of one image over the other is taken as an index of preferential processing (Blake, 2001; Blake \& Logothetis, 2002; Tong, Meng, \& Blake, 2006). BR is a useful method for studying the processes underlying perceptual selection and visual awareness, as stable visual input (i.e., the same images are shown constantly to each eye) leads to alternating conscious percepts. While much of the available literature has focused on how stimulus-based features (e.g., luminance, contrast) impact BR (Blake, 2001), perceiver-based factors also influence perceptual dominance (Anderson et al., 2013, 2011; Tong et al., 2006). As such, BR was utilized in the current study to explore the effects of ostracism (vs. inclusion) on the contents of visual awareness.

Participants initially played Cyberball with two other players, whose faces were displayed during the game. Critically, participants were ostracized by one of the players and included by the other (Williams et al., 2000). Afterwards, the faces of the players were presented together with houses 
in a standard BR task and perceptual dominance was assessed. Based on the assumptions of the ODS (Spoor \& Williams, 2007; Williams \& Nida, 2011), targets associated with ostracism (vs. inclusion) were expected to dominate longest in visual awareness.

\section{Method}

\section{Participants and Design}

Forty-three individuals $(21$ females, mean age $=21.20, S D=1.62)$ took part in the study. ${ }^{2}$ Their participation was voluntary and all had normal or corrected-to-normal visual acuity. Three participants (1 female \& 2 male) failed to follow the instructions during the BR task by responding with invalid key presses, thus were excluded from the analyses. The experiment had a single factor (Target: ostracizer or includer) repeated-measures design and was reviewed and approved by the Ethics Committee at the School of Psychology, University of Aberdeen.

\section{Procedure and Stimulus Materials}

Participants arrived at the laboratory individually, were greeted by a male experimenter, and told they would be performing two tasks. The first task was a ball-toss game called Cyberball (Williams et al., 2000). Cyberball involves a virtual ball being passed between the participant (depicted by an icon on the computer screen) and two other players (depicted in the current study by their faces, see Figure 1). On receiving the ball, participants choose which of the other players would receive it next by means of a mouse click. In reality, however, participants played the game with two computerized confederates: an ostracizer and an excluder. In the current set up, the includer passed the ball to the participant on $50 \%$ of her/his throws; the ostracizer, in contrast, only passed the ball to the participant on a single occasion. In total, the ball was passed 50 times. Players (i.e., faces) in the Cyberball game were taken from the FACES collection at the Max Planck Institute (MPI) for Human

\footnotetext{
${ }^{2}$ An a priori sample size calculation $\left(\mathrm{G}^{*}\right.$ Power $)$ revealed a requirement of 38 participants $(d=0.5, \alpha=0.05$, power $=85 \%)$. An additional $10 \%$ were recruited to allow for drop out.
} 
Development (Ebner, Riediger, \& Lindenberger, 2010); 3 male and 3 female targets with neutral expressions were selected. All faces were grey scale. Participants played the game with same-sex targets $^{3}$ and the faces of the players (i.e., includer or ostracizer) were counterbalanced across the sample.

Next, participants completed a standard BR task. Stimuli (faces and houses) were presented centrally on a Sony 21" Trinitron monitor using a SVGA graphics card (VSG125, Cambridge Research Systems, UK). The monitor was enclosed in a cubicle in a dimly lit room (8 lux) and each participant's head was stabilized using a forehead- and chin-rest. To induce BR, each face and corresponding luminance-matched house was viewed through ferroelectric liquid crystal shutter goggles (FE-1; Cambridge Research Systems, UK), which alternately occluded the two eyes at half of the frame-rate of the monitor $(100 \mathrm{~Hz})$. This resulted in the face and house stimuli being presented to separate eyes. The faces comprised the players (i.e., includer \& ostracizer) from the Cyberball game and the houses were taken from previous research exploring face perception and BR (Bannerman, Milders, de Gelder, \& Sahraie, 2008). The stimuli subtended $2.7^{\circ}$ x $3.6^{\circ}$ of visual angle at a viewing distance of $64 \mathrm{~cm}$ and all were surrounded by a textured border (border width $=0.5^{\circ}$ ). The texture patterns were identical in the left and right eye images in order to facilitate stimulus fusion and impose the stability of vergence. The monitor background luminance viewed through the goggles was $0.13 \mathrm{cdm}^{-2}$ and the mean luminance of face and house images was $6.6 \mathrm{cdm}^{-2}(S D=1.15)$ measured using a luminance meter (Konica Minolta LS100, Japan).

\footnotetext{
${ }^{3}$ Research reveals that ostracism is most potent when triggered by a same-sex player during Cyberball (Bolling, Pelphrey, \& Vander Wyk, 2012).
} 


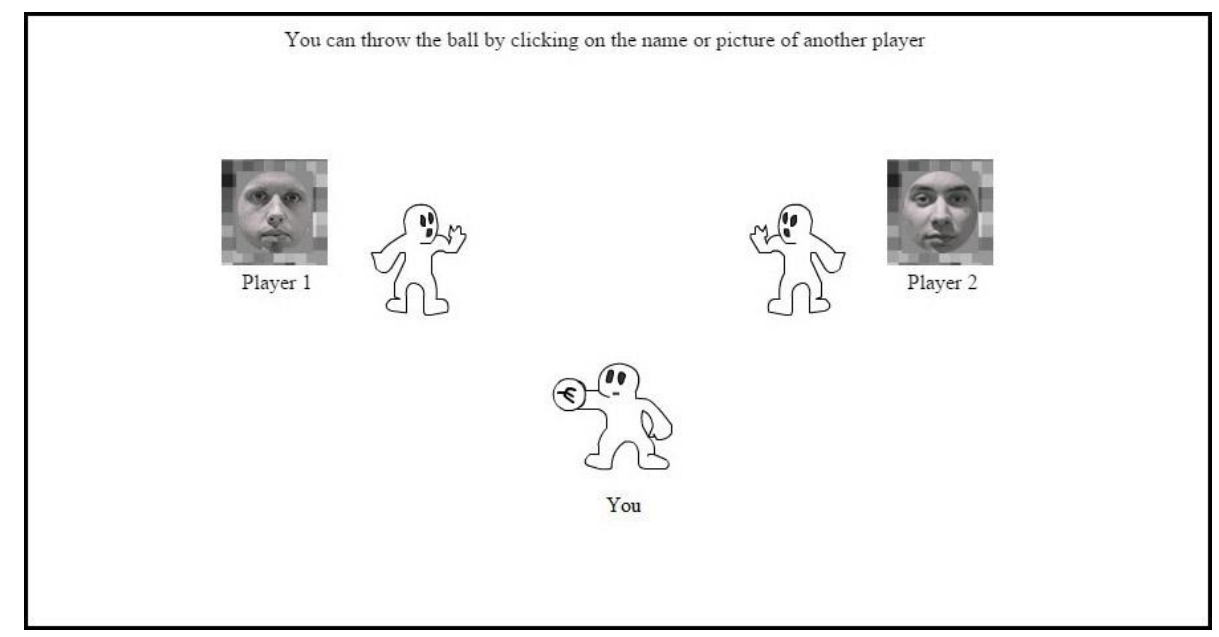

Figure 1. Example of Cyberball game screen.

Participants performed 12 trials in total in three separate blocks ( $3 \times 4$ trials). Each block contained 2 trials in which faces were presented to the left eye and houses to the right eye; in the other 2 trials the assignment was reversed. The sequence of trials in each block was randomized for participants and the duration of each trial was 20 seconds. Trials were separated by 2 seconds of rest during which a blank screen was presented. Prior to the experiment proper, participants were given four practice trials to familiarize them with BR task. Two novel face/house stimulus pairs (from the MPI database) were presented and participants were instructed to report their percepts by pressing and holding one of two response keys when perceiving a face or house. For mixed percepts, participants were required to press and hold down both keys. Following the practice phase, participants completed the experimental trials after which they were debriefed, thanked, and dismissed.

\section{Results}

Following previous research, we measured visual awareness for the target faces using the duration of individual dominance/suppression phases (see Anderson et al., 2011; Zhou, Jiang, He, \& Chen, 2010). For each participant, we calculated the mean duration during which faces (previously 
associated with either ostracism or inclusion) were seen across trials (i.e., mean dominance duration). A paired $t$-test on these data revealed that targets associated with ostracism dominated visual awareness for longer than targets associated with inclusion, $t(39)=2.44, p=.019, d=.38,95 \% \mathrm{CI}$ : $[73,784]$ (see Figure 2). In addition, we also considered the initial predominance of a face (IPF) and the alternation rate (i.e., mean number of percepts per trial) during BR trials (Alpers \& Gerdes, 2007). These were calculated separately for each target. The IPF (i.e., the frequency of first percepts of a face minus the frequency of first percepts of a house divided by the sum of face and house percepts) reveals whether the status of a face affects its immediate selection into visual awareness. Wilcoxin's nonparametric test showed no difference between the IPF ratios for faces associated with ostracism and inclusion $(z=-1.51, p=.062, r=.17) .{ }^{4}$ Alternation rates also did not differ as a function of face type $(t(39)=0.28, p=.777, d=.04,95 \%$ CI: $[-.27, .20]$.

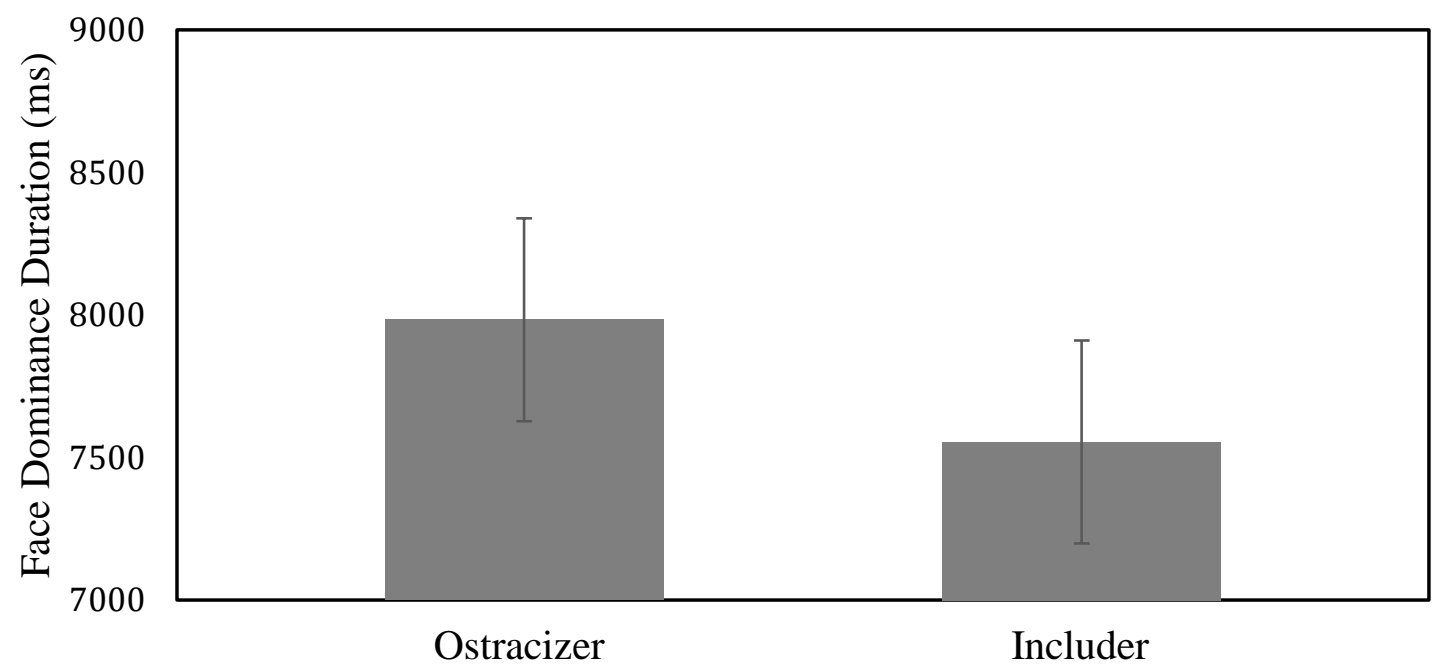

Figure 2. Face dominance as a function of target. Error bars represent the $95 \%$ CIs of the withinparticipants difference between targets.

\footnotetext{
${ }^{4}$ It is unsurprising that the IPF ratios did not differ for faces associated with ostracism and inclusion. Effects on IPF ratios are predominantly driven by structural differences between stimuli (e.g., emotional vs. neutral faces), such that faces with salient local features are perceived first (Alpers \& Gerdes, 2007). Even when faces differ structurally, however, evidence for the emergence of IPF effects is mixed (Bannerman, Regener, \& Sahraie, 2011) and may be restricted to clinical populations (Singer, Eapen, Grillon, \& Ungerleider, 2012). Research comparable to the current study (i.e., effects of social learning on BR) also did not report differences in IPF ratios as a function of face type (i.e., faces associated with desirable or undesirable gossip/behaviors, see Anderson et al., 2011; Mo, Xia, Qin, \& Mo, 2016).
} 


\section{General Discussion}

Using Cyberball (Williams et al., 2000), here we demonstrated the effects of ostracism on attentional processing. Compared to targets associated with prior acts of social inclusion, those linked with ostracism dominated longer in visual awareness during BR. This result is noteworthy for several reasons. First, it provides initial evidence for the operation of an ODS during person perception (e.g., Spoor \& Williams, 2007; Williams, 2009). Second, it extends prior research revealing how facial cues associated with ostracism influence the appraisal and evaluation of conspecifics (e.g., Böckler, Homke, \& Sebanz, 2014; Paolini, Alparone, Cardone, van Beest, \& Merla, 2016; Wirth, Sacco, Hugenberg, \& Williams, 2010). Third, it develops extant research on the effects of social learning on visual processing (Anderson et al., 2011), notably how ostracism impacts the contents of visual awareness. Consideration is now given to each of these issues.

At a theoretical level, the current findings are consistent with the suggestion that dedicated perceptual mechanisms - comprising an ODS (or such like) - sensitize people to the presence of rejection-related cues in the environment (e.g., Kerr \& Levine, 2008; Leary \& Baumeister, 2000; Spoor \& Williams, 2007; Wesselmann, Nairne, \& Williams, 2012; Williams, 2009), an outcome with obvious benefits given the costs of social disconnection (DeWall \& Bushman, 2011; Leary \& Baumeister, 2000). As well as hurting one's feelings, ostracism increases anxiety, sadness, jealousy, and depression. It also diminishes state self-esteem and general psychological wellbeing (Leary, 2010; Williams, 2007). By dominating visual awareness, targets associated with ostracism (vs. inclusion) potentially enable people to take the steps necessary (i.e., trigger compensatory mechanism) to avoid further discomfort (Williams, 2007). That is, by highlighting the presence of rejection-related cues, the ODS facilitates the activation of pre-emptive coping strategies. For example, when people's belongingness needs are not satisfied they display enhanced visual sensitivity to signs of acceptance, such as smiling faces (Bernstein, Young, Brown, Sacco, \& Claypool, 2008; DeWall et al., 2009).

Operating in this way, the ODS resonates with related work exploring the evaluative appraisal of conspecifics (Axelrod, Bar, \& Rees, 2015). Focusing on the rapidity with which affective 
information is extracted from faces (Adams, Gray, Garner, \& Graf, 2010; Morris, Öhman, \& Dolan, 1998), this research points to a preconscious mechanism that preferentially detects evolutionarily relevant expressions. Indeed, it has been suggested that a dedicated subcortical mechanism involving the amygdala and superior colliculus supports rapid detection of threatening stimuli (Tamietto \& de Gelder, 2010; Vuilleumier, 2005). Of course, to confirm the operation of the ODS outside the laboratory and elucidate the supporting neural architecture additional research will be required. What the current findings unambiguously demonstrate, however, is that in addition to influencing a range of cognitive and emotional outcomes (DeWall \& Bushman, 2014; Hartgerink, et al., 2015; Willams, 2007), ostracism also impacts perceptual processing.

It is not only (structurally distinct) facial expressions that signal the relevance of undesirable targets. Our social worlds are replete with individuals that have acquired affective significance through their specific deeds, including acts of ostracism (Leary \& Baumeister, 2000; Williams, 2007). As the current results revealed, absent triggering facial expressions, targets such as these are given processing priority during the person perception process (Anderson et al., 2011; Jiang, Costello, Fang, Huang, \& He, 2006; Shilling \& Brown, 2016). Influenced by a combination of stimulus-driven features and topdown factors (e.g., goals, expectancies, learned associations), the current effects are likely mediated by the priority maps that guide visuomotor behavior (Fecteau \& Munoz, 2006). Priority maps associated with dorsal stream visual areas, such as the lateral intraparietal area (LIP) and frontal eye field (FEF), are less affected by interocular suppression than ventral stream areas involved in conscious face recognition (Fang \& He, 2005), suggesting a pathway through which person-related knowledge may influence competition for conscious access.

Using BR, here we showed that ostracism influences perceptual dominance, such that targets associated with prior acts of exclusion dominate visual awareness for longer than their counterparts associated with acts of inclusion. As this effect emerged during the perceptual-alteration-cycle however (i.e., a phase in which images drop in and out of visual awareness, hence are potentially subject to conscious processing strategies), it remains to be seen if ostracism impacts the pre-attentive 
stages of the person perception process (Sterzer, Stein, Ludwig, Rothkirch, \& Hesselmann, 2014; Yang, Brascamp, Kang, \& Blake, 2014). To bolster and extend the current findings, a useful task for future research will therefore be to investigate the effects of ostracism on person perception using complementary methodologies, such as breaking continuous flash suppression (b-CFS). A variant of $\mathrm{BR}, \mathrm{b}-\mathrm{CFS}$ was devised to probe the ability of invisible stimuli to overcome interocular suppression and access awareness (Tsuchiya \& Koch, 2005). During CFS, high-contrast dynamic patterns (e.g., Mondrian images) are flashed to one eye, rendering stationary stimuli (e.g., faces) presented to the other eye invisible for extended durations. The time taken to break interocular suppression and become visible reveals the relative potency of a stimulus, such that shorter suppression times reflect stronger unconscious processing (Yang et al., 2014). Based on the current results, one would expect targets associated with ostracism (vs. inclusion) to overcome interocular suppression and access visual awareness most rapidly.

In a complex world, one of the primary determinants of social-cognitive processing is the selfrelevance of conspecifics. Here, the nature of the relationship between self and others was manipulated via experiences of inclusion or ostracism during a virtual ball-tossing game (Williams et al., 2000). Outside the laboratory, however, targets acquire affective significance in a multitude of ways that vary both in magnitude and duration. Whereas some targets have longstanding personal relevance (e.g., family members, friends, foes), others only temporary meaning through shared experiences (e.g., adjacent passengers on a flight) or current task objectives (e.g., asking someone for directions). Of theoretical interest, therefore, is the extent to which degrees (and types) of self-relevance moderate access to visual awareness. Elsewhere, researchers have revealed potent self-biases in perceptual processing (Sui, He, \& Humphreys, 2012; Sui \& Humphreys, 2015). Sui et al. (2012), for example, have shown that simple perceptual responses (i.e., matching judgments) to pairs of shapes are facilitated when the stimuli are associated with self (e.g., circle = you) rather than another familiar person (e.g., square $=$ friend). By extrapolation, one would therefore expect self-relevance to exert a 
regulatory influence on access to visual awareness both for persons and objects, a possibility that awaits empirical consideration.

Based on applications of Cyberball (Williams et al., 2000), a voluminous literature has revealed how ostracism affects an ever-increasing range of interpersonal (e.g., helping behavior, charitable donations, acts of aggression) and intrapersonal (e.g., self-esteem, self-control, physiological reactivity) outcomes (Hartgerink et al., 2015). Of particular interest in the current context are the effects observed on physiological measures. For example, amongst other things, ostracism has been shown to elevate levels of cortisol (Blackhart, Eckel, \& Tice, 2007; Zwolinski, 2008), heart rate, respiratory sinus arrhythmia, and skin conductance (Iffland, Sansen, Catani, \& Neiner, 2014; Murray-Close, 2011). Intriguingly, recent work has shown that these effects extend to non-invasive measures of autonomic activity (e.g., functional infrared imaging, fIRI) that record the thermal signals spontaneously released by the body. In an ingenious experiment, Paolini et al. (2016) demonstrated an increase in facial temperature around the nose and mouth in response to ostracism (vs. inclusion) during a game of Cyberball.

Expanding work of this kind to the perceptual-attentional domain, here we showed that people are sensitively attuned to targets associated with prior acts of ostracism. In so doing, the current findings resonate with previous work documenting the importance of facial cues (i.e., eye gaze, emotional expressions) to feelings of ostracism and relational devaluation (e.g., Böckler et al., 2014; Wirth et al., 2010). Based on the viewpoint that an evolved mechanism — the sociometer — continuously monitors the social environment for cues indicative of rejection (Leary, 1999; Leary \& Baumeister, 2000), Wirth et al. (2010) speculated that participants would use an interaction partner's gaze direction (i.e., direct or averted) as a signal of potential interest or disinterest. The results confirmed their prediction. Compared to receiving direct eye contact, participants in receipt of averted gaze felt ostracized by their partner (see also Böckler et al., 2014). Similarly, periods of unexpected silence can also signal an implicit threat to one's inclusion within a group (Koudenburg, Postmes, \& Gordijn, 2011, 2013). At a different point in the processing chain, the current findings suggest that 
targets associated with ostracism (i.e., those displaying averted gaze or who have given one the silent treatment) should gain privileged access to conscious awareness when encountered at a later date. An important task for future research will be to elucidate how basic perceptual and attentional operations drive both the detection of ostracism and people's subsequent reactions to individuals by whom they have been ostracized.

In sum, certain classes of stimuli benefit from enhanced processing. During early stages of perception - specifically the resolution of binocular rivalry — here we showed that targets associated with prior acts of ostracism (vs. inclusion) dominated visual awareness. As DeWall and Bushman (2011, p. 259) have observed, “...the social acceptance and rejection literature offers fertile ground for psychological scientists to unlock the mysteries underlying the need to belong — and how satisfying or thwarting this need gives insight into human nature." Where visual awareness is concerned, the mind appears to be attentive to those by whom we have been ostracized. 


\section{References}

Adams, W.J., Gray, K.L., Garner, M., \& Graf, E.W. (2010). High-level face adaptation without awareness. Psychological Science, 21, 205-210.

Alpers, G.W., \& Gerdes, A.B. (2007). Here is looking at you: Emotional faces predominate in binocular rivalry. Emotion, 7, 495-506.

Anderson, E.C., Dryman, M.T., Worthington, J., Hoge, E.A., Fischer, L.E., Pollack, M.H., Barrett, L.F., \& Simon, N.M. (2013). Smiles may go unseen in generalized social anxiety disorder: Evidence from binocular rivalry for reduced consciousness of positive facial expressions. Journal of Anxiety Disorders, 27, 619-626.

Anderson, E., Siegel, E.H., Bliss-Moreau, E., \& Barrett, L.F. (2011). The visual impact of gossip. Science, 332, 1446-1448.

Axelrod, V., Bar, M., \& Rees, G. (2015). Exploring the unconscious using faces. Trends in Cognitive Sciences, 19, 35-45.

Bannerman, R.L., Milders, M., de Gelder, G., \& Sahraie, A. (2008). Influence of emotional facial expressions on binocular rivalry. Opthalmic and Physiological Optics, 28, 317-326.

Bannerman, R.L., Regener, P., \& Sahraie, A. (2011). Binocular rivalry: A window into emotional processing in aging. Psychology and Aging, 26, 372-380.

Bar, M. (2004). Visual objects in context. Nature Reviews Neuroscience, 5, 617-629.

Baumeister, R.F., DeWall, C.N., Ciarocco, N.J., \& Twenge, J.M. (2005). Social exclusion impairs self-regulation. Journal of Personality and Social Psychology, 88, 589-604.

Baumeister, R.F., \& Leary, M.R. (1995). The need to belong: Desire for interpersonal attachments as a fundamental human motivation. Psychological Bulletin, 117, 497-529. Baumeister, R.F., Twenge, J.M., \& Nuss, C.K. (2002). Effects of social exclusion on cognitive processes: Anticipated aloneness reduces intelligent thought. Journal of Personality and Social Psychology, 83, 817-827. 
Bernstein, M.J., Young, S.G., Brown, C.M., Sacco, D.F., \& Claypool, H.M. (2008). Adaptive responses to social exclusion: Social rejection improves detection of real and fake smiles. Psychological Science, 19, 981-983.

Blackhart, G.C., Eckel, L.A., \& Tice, D.M. (2007). Salivary cortisol in response to acute social rejection and acceptance by peers. Biological Psychology, 75, 267-276

Blake, R. (2001). A primer on binocular rivalry, including current controversies. Brain and Mind, 2, 5-38.

Blake, R., \& Logothetis, N.K. (2002). Visual competition. Nature Reviews Neuroscience, 3, $13-21$.

Böckler, A., Hömke, P., \& Sebanz, N. (2014). Invisible man: Exclusion from shared attention affects gaze behavior and self-reports. Social Psychological and Personality Science, 5, 140-148.

Bolling, D.Z., Pelphrey, K.A., \& Vander Wyk, B.C. (2012). Differential brain responses to social exclusion by one's own versus opposite gender peers. Social Neuroscience, 7, 331-346.

Collins, J.A., \& Olson, I.R. (2014). Knowledge is power: How conceptual knowledge transforms visual cognition. Psychonomic Bulletin \& Review, 21, 843-860.

Craighead, W.E., Kimball, W.H., \& Rehak, P.J. (1979). Mood changes, physiological responses, and self-statements during social rejection memory. Journal of Consulting and Clinical Psychology, 47, 385-396.

Critcher, C.R., \& Zayas, V. (2014). The involuntary excluder effect: Those included by an excluder are seen as exclusive themselves. Journal of Personality and Social Psychology, 107, 454-474.

DeWall, C.N., \& Bushman, B.J. (2011). Social acceptance and rejection: The sweet and the bitter. Current Directions in Psychological Science, 20, 256-260. 
DeWall, C.N., Maner, J.K., \& Rouby, D.A. (2009). Social exclusion and early-stage interpersonal perception: Selective attention to signs of acceptance. Journal of Personality and Social Psychology, 96, 729-741.

Dunning, D., \& Balcetis, E. Wishful seeing: How preferences shape visual perception. Current Directions in Psychological Science, 22, 33-37.

Eisenberger, N.I. (2012). The pain of social disconnection: Examining the share underpinnings of physical and social pain. Nature Reviews Neuroscience, 13, 421-434.

Erbner, N.C., Riediger, M., \& Lindenberger, U. (2010). FACES - A database of facial expressions in young, middle-aged, and older women and men: Development and validation. Behavior Research Methods, 42, 351-362.

Fang, F., \& He, S. (2005). Cortical responses to invisible objects in the human dorsal and ventral pathways. Nature Neurocience, 10, 1380-1385.

Fecteau, J.H., \& Munoz, D.P. (2006). Salience, relevance, and firing: A priority map for target selection. Trends in Cognitive Sciences, 10, 382-390.

Gardner, W., Pickett, C.L., \& Brewer, M.B. (2000). Social exclusion and selective memory: How the need to belong influences memory for social events. Personality and Social Psychology Bulletin, 26, 486-496.

Hartgerink, C.H.J., van Beest, I., Wicherts, J.M., \& Williams, K.D. (2015). The ordinal effects of ostracism: A meta-analysis of 120 Cyberball studies. PLOS ONE, 10, e0127002.

Iffland, B., Sansen, L.M., Catani, C., \& Neuner, F. (2014). Rapid heartbeat, but dry palms: Reactions of heart rate and skin conductance levels to social rejection. Frontiers in Psychology, 5:956. Doi. 10.3389/fpsyg.2014.00956.

Jiang, Y., Costello, P., Fang, F., Huang, M., \& He, S. (2006). A gender- and sexual orientation-dependent spatial attention effect of invisible images. Proceedings of the National Academy of Sciences, 103, 17048-17052. 
Kerr, N.L., \& Levine, J.M. (2008). The detection of social exclusion: Evolution and beyond. Group Dynamics, Theory, Research, and Practice, 12, 39-52.

Koudenburg, N., Postmes, T., \& Gordijn, E.H. (2011). Disrupting the flow: How brief silences in group conversations affect social needs. Journal of Experimental Social Psychology, 47, 512515.

Koudenburg, N., Postmes, T., \& Gordijn, E.H. (2013). Resounding silences: Subtle norm regulation in everyday interactions. Social Psychology Quarterly, 76, 224-241.

Leary, M.R., (1999). Making sense of self-esteem. Current Directions in Psychological Science, 8 , $32-35$.

Leary, M.R. (2010). Affiliation, acceptance, and belonging. In S.T. Fiske, D.T. Gilbert, \& G. Lindzey (Eds.), Handbook of Social Psychology (5 ${ }^{\text {th }}$ Ed., Vol. 2, pp. 864-897). New York, NY: Wiley.

Leary, M.R., \& Baumeister, R.F. (2000). The nature and function of self-esteem: Sociometer theory. Advances in Experimental Social Psychology, 32, 1-62.

Leary, M.R., Kowalski, R.M., Smith, L., \& Phillips, S. (2003). Teasing, rejection, and violence: Case studies of the school shootings. Aggressive Behavior, 29, 202-214.

Lupyan, G. (2015). Cognitive penetrability of perception in the age of prediction: Predictive systems are penetrable systems. Review of Philosophy and Psychology, 6, 547-569.

Maner, J.K., DeWall, C.N., Baumeister, R.F., \& Schaller, M. (2007). Does social exclusion motivate interpersonal reconnection? Resolving the "porcupine problem." Journal of Personality and Social Psychology, 92, 42-55.

Mo, C., Xia, T., Qin, K., \& Mo, L. (2016). Natural tendency towards beauty in humans: Evidence from binocular rivalry. PLoS ONE 11(3): e0150147.

Morris, J.S., Öhman, A., \& Dolan, R.J. (1998). Conscious and unconscious emotional learning in the human amygdala. Nature, 393, 467-470. 
Murray-Close, D. (2011). Autonomic reactivity and romantic relational aggression among female emerging adults: Moderating roles of social and cognitive risk. International Journal of Psychophysiology, 80, 28-35.

Nezlek, J.B., Kowalski, R.M., Leary, M.R., Blevins, T., \& Holgate, s. (1997). Personality moderators of reactions to interpersonal rejection: Depression and trait self-esteem. Personality and Social Psychology Bulletin, 23, 1235-1244.

Oaten, M., Williams, K.D., Jones, A., \& Zadro, L. (2008). The effects of ostracism on selfregulation in the socially anxious. Journal of Clinical and Social Psychology, 27, 471- 504.

Paolini, D., Alparone, F.R., Cardone, D., van Beest, I., \& Marla, A. (2016). The face of ostracism: The impact of social categorization on the thermal facial responses of the target and the observer. Acta Psychologica, 163, 65-73.

Pickett, C.L., \& Gardner, W.L. (2005). Then social monitoring system: Enhanced sensitivity to social cues as an adaptive response to social exclusion. In K.D. Williams, J.P. Forgas, \& W. \& von Hippel (Eds.), The social outcast: Ostracism, social exclusion, rejection, and bullying (pp. 213-226). New York: Psychology Press.

Pickett, C.L., Gardner, W.L., \& Knowles, M. (2004). Getting a cue: The need to belong and enhanced sensitivity to social cues. Personality and Social Psychology Bulletin, 30, 1095-1107. Romero-Canyas, R., \& Downey, G. (2005). Rejection sensitivity as a predictor of affective and behavioral responses to interpersonal stress: A defensive motivation system. In K.D. Williams, J.P. Forgas, \& W. von Hippel (Eds.), The social outcast: Ostracism, social exclusion, rejection, and bullying (pp. 131-154). New York: Psychology Press.

Sacco, D.F., Wirth, J.H., Hugenberg, K., Chen, Z., \& Williams, K.D. (2011). The world in black and white: Ostracism enhances the categorical perception of social information. Journal of Experimental Social Psychology, 47, 836-842.

Shilling, A.A., \& Brown, C.M. (2016). Goal-driven resource redistribution: An adaptive response to social exclusion. Evolutionary Behavioral Sciences, 10, 149-167. 
Singer, N., Eapen, M., Grillon, C., \& Ungerleider, L.G. (2012). Through the eyes of anxiety: Dissecting threat bias via emotional-binocular rivalry. Emotion, 12, 960-969.

Spoor, J., \& Williams, K.D. (2007). The evolution of an ostracism detection system. In J.P. Forgas, M. Haselton, \& W. von Hippel (Eds.), Evolution and the social mind: Evolutionary psychology and social cognition (pp. 279-292). New York, NY: Psychology Press.

Sterzer, P., Stein, T., Ludwig, K., Rothkirch, M., \& Hesselmann, G. (2014). Neural processing of visual information under interocular suppression: A critical review. Frontiers in Psychology, 5:453. doi: 10.3389/fpsyg.2014.00453.

Sui, J., He, X., \& Humphreys, G.W. (2012). Perceptual effects of social salience: Evidence from self-prioritization effects on perceptual matching. Journal of Experimental Psychology: Human Perception and Performance, 38, 1105-1117.

Sui, J., \& Humphreys, G.W. (2015). The integrative self: How self-reference integrates perception and memory. Trends in Cognitive Sciences, 19, 719-728.

Tamietto, M., \& de Gelder, B. (2010). Neural bases of the non-conscious perception of emotional signals. Nature Reviews Neuroscience, 11, 697-709.

Tong, F., Meng, M., \& Blake, R. (2006). Neural bases of binocular rivalry. Trends in Cognitive Sciences, 10, 502-511.

Tsuchiya, N., \& Koch, C. (2005). Continuous flash suppression reduces negative afterimages. Nature Neuroscience, 8, 1096-1101.

Vuilleumier, P. (2005). How brains beware: Neural mechanisms of emotional attention. Trends in Cognitive Sciences, 9, 585-594.

Wesselmann, E.D., Nairne, J.S., \& Williams, K.D. (2012). An evolutionary social psychological approach to studying the effects of ostracism. Journal of Social, Evolutionary, and Cultural Psychology, 6, 309-328.

Williams, K.D. (2007). Ostracism. Annual Review of Psychology, 58, 425-452. 
Williams, K.D. (2009). Ostracism: A temporal need-threat model. Advances in Experimental Social Psychology, 41, 279-314.

Williams, K.D., Cheung, C.K.T., \& Choi, W. (2000). Cyberostracism: Effects of being ignored over the Internet. Journal of Personality and Social Psychology, 79, 748-762.

Williams, K.D., \& Nida, S.A. (2011). Ostracism: Consequences and coping. Current Directions in Psychological Science, 20, 71-75.

Wirth, J.H., Sacco, D.F., Hugenberg, K., \& Williams, K.D. (2010). Eye gaze and relational evaluation: Averted eye gaze leads to feelings of ostracism and relational devaluation. Personality and Social Psychology Bulletin, 36, 869-882.

Yang, E., Brascamp, J., Kang, M.S., \& Blake, R. (2014). On the use of continuous flash suppression for the study of visual processing outside of awareness. Frontiers in Psychology, 5:724. doi: 10.3389/fpsyg.2014.000724.

Zhou, W., Jiang, Y., He, S., \& Chen, D. (2010). Olfaction modulates visual perception in binocular rivalry. Current Biology, 20, 1356-1358.

Zwolinski, J. (2008). Biopsychosocial responses to social rejection in targets of relational aggression. Biological Psychology, 79, 260-267. 